\title{
Cooling cows with sprinklers: Timing strategy affects physiological responses to heat load
}

\author{
Grazyne Tresoldi, ${ }^{* 1}$ Karin E. Schütz,† and Cassandra B. Tucker ${ }^{\star 2}$ \\ ${ }^{*}$ Center for Animal Welfare, Department of Animal Science, University of California, Davis 95616 \\ †AgResearch Ltd., Hamilton 3240, New Zealand
}

\begin{abstract}
After shade, sprayed water is the most common heat abatement resource provided in dairy farms in the western United States, but little is known about how to manage this resource to improve cow cooling and water-use efficiency. Our objective was to evaluate the cooling effectiveness of 4 spray strategies, using 2 water volumes (approximately 74 or $44 \mathrm{~L} /$ nozzle) over 45 min. Strategies varied based on spray frequency (using the same water volume) and the time that water was on and off (using different water volumes). In a crossover design, 20 Holstein cows (milk yield: $38.9 \pm 4.2 \mathrm{~kg} / \mathrm{d}$ ) were restrained in shaded head gates and tested twice for each control (shade only) and 4 spray treatments (minutes water on $\mid$ off, frequency: number of cycles/45 min): 1.5 on $\mid 3$ off, 10 cycles; 1.5 on 6 off, 6 cycles; 3 on 6 off, 5 cycles; and 3 on 12 off, 3 cycles (water temperature average \pm standard deviation: $26 \pm 2^{\circ} \mathrm{C}$ ). Air temperature and humidity averaged $29 \pm 5^{\circ} \mathrm{C}$ and $26 \pm 13 \%$, respectively, during testing periods. Body temperature (BT), respiration rate (RR), skin temperature of the leg and shoulder, and air temperature surrounding the cow were measured. Compared with shade alone, all water treatments reduced heat load in cattle. Body temperature, for example, was at least $0.3^{\circ} \mathrm{C}$ lower (maximum reduction: $0.5^{\circ} \mathrm{C}$ ) for sprayed cows after $45 \min \left(39.0\right.$ vs. $\left.\leq 38.7^{\circ} \mathrm{C}\right)$. The only change associated with spraying cows more often using the same water volume (thus manipulating both times on and off) was that applying water more frequently tended to reduce RR by 7 breaths/min. On the other hand, manipulating either time on or off (thus, water volume) affected most responses. Increasing the time on from 1.5 to 3 min (time off: $6 \mathrm{~min}$ ) or shortening the time off from 12 to 6 min (time on: 3 min) or from 6 to 3 min (time on:
\end{abstract}

Received April 12, 2018.

Accepted July 25, 2018.

${ }^{1}$ Present address: College of Agriculture, California State University, Chico 95929 .

${ }^{2}$ Corresponding author: cbtucker@ucdavis.edu
$1.5 \mathrm{~min}$ ) reduced $\mathrm{BT}$ by at least $0.1^{\circ} \mathrm{C}$ (maximum reduction: $0.2^{\circ} \mathrm{C}$ ) and leg temperature by $\geq 0.2^{\circ} \mathrm{C}$ after 45 min. Shortening the time off also tended to reduce RR (7 breaths/min). Similarly, shoulder and surrounding air temperatures were, respectively, 0.5 and $0.4^{\circ} \mathrm{C}$ lower when reducing the time off from 6 to $3 \mathrm{~min}$. In conclusion, applying the same water volume more often had minimal effects on responses to heat load on restrained cattle over a 45-min period. In contrast, spraying cows for longer or reducing the time off (thus, using more water) improved cow cooling compared with strategies that used less water.

Key words: soakers, spray duration, time on and off, heat stress

\section{INTRODUCTION}

Exposure to heat load is a major sustainability concern for the US dairy industry (von Keyserlingk et al., 2013). Although farmers often provide their cows with heat abatement resources (e.g., shade, sprayed water, and fans; USDA, 2016), the industry still loses millions of dollars annually due to reduced milk production, infertility, and poor health during the summer months (St-Pierre et al., 2003; Stull et al., 2008). Some of these losses can be attributed to the failure of heat abatement. Milk production, for example, can be reduced depending on the quantity and type of heat abatement resources provided (e.g., Keister et al., 2002; Urdaz et al., 2006; Chen et al., 2016). This suggests that optimizing management practices associated with the provision of such resources is important to enhance cow welfare and profitability of dairy systems.

After shade, sprayed water is the most common heat abatement resource provided on dairy farms in the western United States (USDA, 2016). Although water reduces heat load in cattle more effectively than shade (Kendall et al., 2007; Chen et al., 2013, 2016), little research has focused on how spray strategies affect cow cooling and water-use efficiency. In a survey conducted on California drylot dairies, we found that the quantity of water used to cool cows was affected by flow 
rate, spray timing, and nozzle:cow ratio (Tresoldi et al., 2017). On the dairies we studied, cattle responses to heat load also varied. Respiration rates (RR), for example, ranged from 65 (normal) to 95 breaths/min (high) across farms in the afternoon. This variation in RR suggests that opportunities exist to optimize cooling and water-use efficiency. As other studies have found that flow rates $\geq 1.3 \mathrm{~L} / \mathrm{min}$ have a minimal effect on cow cooling in different climates (Means et al., 1992; Chen et al., 2015, 2016), adjusting spray timing could be an effective strategy to achieve better welfare and production outcomes while using less water.

Spray timing is a function of the spray duration (i.e., time on) and the time interval when the coat is left to dry (i.e., time off). These strategies (i.e., time on and off) either alone or together can affect the frequency with which water is sprayed (i.e., number of cycles within a given time interval). Manipulating times on and off are thought to affect cow cooling. During time on, as the spray soaks the coat, it is expected that the dripping water carries heat away from the body. During time off, it is expected that cows lose heat when converting the liquid water into vapor (Hillmann et al., 2001; Gebremedhin and $\mathrm{Wu}, 2002)$.

Only a few studies have evaluated how spray timing affects measures of heat load in cattle, and the picture they present is mixed. Although it is widely accepted that most of the heat losses in cattle occur when the water is off, several studies have indicated that relatively little change in physiological responses occurs during this period. For example, we found that physiological responses to heat load increased once water was turned off, regardless of spray duration (Tresoldi et al., 2018). Brouk et al. (2003) also found that RR and body temperature (BT) were lower in treatments where less time elapsed between spray applications (4 vs. 9 or $14 \mathrm{~min}$ off, $1 \mathrm{~min}$ on), indicating that leaving more time for the soaked water to evaporate may not optimize physiological responses to heat load. In addition, the time it takes for the coat to dry after the water is turned off differs across studies. It ranges from 14 to 16 min (Perano et al., 2015; Tresoldi et al., 2018) to 4.5 min (Flamenbaum et al., 1986), and likely depends on environmental conditions, such as airflow and air temperature (AT). In terms of the cooling effects while water is being sprayed, we have found that a single spray application has to last at least $3 \mathrm{~min}$ for there to be cooling (Tresoldi et al., 2018). However, others have shown that increasing spray duration from 10 to only 20 or $30 \mathrm{~s}$ (every $4.5 \mathrm{~min}$ ) resulted in more markedly reduced physiological responses in cattle after multiple spray applications (Flamenbaum et al., 1986). Across the research evaluating both times on and off, the reduction in $\mathrm{RR}$ and $\mathrm{BT}$ cannot be attributed only to timing, because all experiments confounded patterns of timing with water volume. In addition, in some of these studies, the strategies tested reduced responses to heat load but did not result in cool cows. For example, in 2 of these studies, BT was $\geq 39.1^{\circ} \mathrm{C}$ at the end of any water treatment (Flamenbaum et al., 1986; Brouk et al., 2003). Similar BT was recorded in cows with no access to sprinklers throughout the day (Chen et al., 2013), suggesting these strategies were, in total, insufficient.

To address these gaps in the literature, the effects of spray timing and water volume need to be disentangled. That is, both times on and off should be manipulated, because this affects spray frequency. This then needs to be considered not only in terms of the immediate effects on cow physiology, but also in the context of the level of cooling achieved. Thus, the objective of this study was to evaluate the cooling effectiveness of 4 spray strategies using 2 water volumes over a 45min period of time, which varied based on (a) spray frequency, and times (b) on and (c) off.

\section{MATERIALS AND METHODS}

\section{Animals and Housing}

This study was conducted between August and September 2015 at the University of California, Davis Dairy Teaching and Research Facility, and all procedures were approved by the Institutional Animal Care and Use Committee. Two cohorts of 10 lactating Holstein cows averaging (mean $\pm \mathrm{SD}$ ) $38.9 \pm 4.2 \mathrm{~kg} / \mathrm{d}$ of milk, $211 \pm 86$ DIM, and $2.1 \pm 1.3$ lactations were used ( $\mathrm{n}=20$ cows).

In each cohort, cows were split in 2 groups of 5 cows each, balanced for milk production, and kept in concrete-floored pens that were divided by removable fencing panels (Power River, Provo, UT) and plywood (at the feed bunk area; $2.4 \mathrm{~m}$ high $\times 3.7 \mathrm{~m}$ long). In each pen, cows had access to a water trough (automatically refilled), shaded feed bunk, and sand-bedded freestalls. In between milkings (1900 to $0700 \mathrm{~h}$ ), fencing panels were open and all cows remained together. Cows were fed a TMR ad libitum twice daily. In the home pen, cooling was provided through 2 fans positioned above the stalls and sprayed water at the feed bunk line (TFVP7.5 Turbo FloodJet wide-angle flat spray tip, flow rate: 4.9 L/min; Spraying Systems Co., Wheaton, IL).

\section{Experimental Design}

Cows were tested $35 \mathrm{~m}$ away from the home pen in 5 individual testing pens measuring 3.6 by $2.4 \mathrm{~m}$ (length $\times$ width), which were built using fencing panels 
(described above) and enclosed with plywood to prevent water drift across pens. Two white canopy tents (orientation: $\mathrm{N}-\mathrm{S}$; $3.4 \mathrm{~m}$ high, total length $\times$ width: 18 $\times 6 \mathrm{~m}$, polyethylene $180 \mathrm{~g} / \mathrm{m}^{2}$; Delta Canopy, McKinney, TX) were placed side by side to shade the testing area. Fans were not provided in this area. Cows were restrained using the head gates of the feed bunk, where fresh water and feed (TMR topped with grain and alfalfa hay) were provided. In each testing pen, spray water was mounted at the center of the pen 2 $\mathrm{m}$ above the floor. To generate a flow rate of $4.9 \mathrm{~L}$ of water/min, the spray water apparatus consisted of a nozzle (described above) and a 207-kPa water pressure regulator (PR55-30; Hendrickson Bros., Corona, CA). This flow rate was chosen to minimize the quantity of smaller droplets generated by the spray and, consequently, water drift.

The 4 spray strategies varied in terms of water volume (approximately 74 vs. $44 \mathrm{~L} /$ nozzle) and number of cycles (from 3 to 10 cycles), which was a product of different combinations of time that water was on $(1.5$ or $3 \mathrm{~min})$ and off $(12,6$, or $3 \mathrm{~min})$ as described in Table 1. Time on was chosen to allow water to drip from the coat (1.5 min) and to deliver twice this amount (3 min). Time off was chosen to allow the coat to dry (12 min, based on Tresoldi et al., 2018) and 50 and $25 \%$ of this time (6 and $3 \mathrm{~min}$, respectively). The control treatment received only shade. If considering that each nozzle can spray up to 3 cows at the time (as suggested by Chen et al., 2015 and Tresoldi et al., 2017), the quantity of water used hourly per cow in this study ranged from 19.6 to $33.6 \mathrm{~L} /$ cow per hour.

Each group of cows was tested starting at either 1130 or $1430 \mathrm{~h}$ for $10 \mathrm{~d}$. Water was manually turned on and off. Sprinklers in the home pen were turned off $30 \mathrm{~min}$ before moving the cattle to the testing area to ensure that their coats were dry, and only turned on $3 \mathrm{~h}$ after their return to determine the effect of treatments on BT (Chen et al., 2015). Cows were moved to the testing area $30 \mathrm{~min}$ before receiving a 45 -min treatment. All treatments were tested each day in both groups, and each treatment was replicated twice per cow during the trial. The order in which each cow received each treatment in each replicate was balanced and random- ized without replacement using unique permutations. Individual cows were tested at the same time each day.

\section{Physiological Measures}

Body temperature was recorded intravaginally every 1 min using data loggers (DST centi-T, accuracy: $\pm 0.1^{\circ} \mathrm{C}$, resolution: $\pm 0.032^{\circ} \mathrm{C}$; Star-Oddi, Gardabaer, Iceland) attached to a shortened, hormone-free controlled internal drug release insert (DEC International NZ Ltd., Hamilton, New Zealand). The data loggers recorded $\mathrm{BT}$ at all times that cows were enrolled in the trial.

Respiration rate was measured as time for 10 flank movements and converted to breaths per minute to facilitate comparisons with other studies. This measure was recorded immediately before and after each water spray application and at the end of treatment. Data were collected by 14 observers. Inter-observer reliability was calculated using regression analysis for $R R\left(R^{2} \geq\right.$ $0.92, P<0.001$; intercept $=-0.36$ to $0.68, P \geq 0.05$; slope $=0.96$ to $1.04, P \geq 0.05)$.

Skin temperature was measured every 1 min using temperature loggers (Thermochron iButton DS1921HF5, accuracy: $\pm 1.0^{\circ} \mathrm{C}$, resolution: $\pm 0.125^{\circ} \mathrm{C}$; Embedded Data Systems, Lawrenceburg, KY) placed in 2 locations on the left side of the cow: $5 \mathrm{~cm}$ behind the caudal angle of the scapula ("shoulder") and in the medial inner face of the ulna and radius, $12 \mathrm{~cm}$ below the axilla ("upper leg"). In both areas, 10- × 10-cm patches of hair were shaved, and the loggers were placed inside a clear 5 - $\times 5$-cm reclosable bag, and then attached to the skin using 1 layer of surgical tape $(7.6 \mathrm{~cm}$ wide; $3 \mathrm{M}$ Micropore, St. Paul, MN). Cobalt chloride-embedded paper $(2.5 \times 5 \mathrm{~cm}$; Indigo Instruments, Waterloo, $\mathrm{ON})$ was used to identify wet data loggers at the upper leg (inter-observer reliability $\kappa \geq 0.93$ ) before and after each spray application. If moisture was found, data from these time points were excluded.

\section{Spray Water Measures}

Sprayed water temperature was measured every 1 $\mathrm{s}$ at the nozzle outlet using a thermocouple (TJC36-

Table 1. Characteristics of the 4 spray treatments used and a shade-only control

\begin{tabular}{|c|c|c|c|c|c|}
\hline \multirow[b]{2}{*}{ Characteristic } & \multirow[b]{2}{*}{ Control } & \multicolumn{4}{|c|}{ Treatment (min on $\mid$ off) } \\
\hline & & $1.5 \mid 3$ & $3 \mid 6$ & $1.5 \mid 6$ & $3 \mid 12$ \\
\hline Water volume (L/nozzle) & 0 & 74 & 74 & 44 & 44 \\
\hline Number of cycles/45 min & 0 & 10 & 5 & 6 & 3 \\
\hline Spray duration (time on, min) & 0 & 1.5 & 3 & 1.5 & 3 \\
\hline Time off $(\mathrm{min})$ & 0 & 3 & 6 & 6 & 12 \\
\hline
\end{tabular}


CPSS-062G-6-SMP-M) housed in a ceramic insulator (ORX-116316-6), attached to a temperature data logger (OM-CP-TC101A, accuracy: $\pm 0.5^{\circ} \mathrm{C}$, resolution: $\pm 0.1^{\circ} \mathrm{C}$ ) stored in a waterproof case (OM-CP-WATERBOX101A; all products from Omega Engineering Inc., Stamford, CT).

\section{Environmental Conditions}

To measure the microclimate surrounding the cow (from $-1 \mathrm{~min}$ to $45 \mathrm{~min}$ ), a temperature data logger (as described for skin temperature) was attached next to the upper leg logger, in the caudal face of the ulna, using a piece of styrofoam cut in a "L" shape $(8 \times$ $12 \mathrm{~cm}$ long, $2 \mathrm{~cm}$ wide). This approach allowed us to use the same device to measure both air and skin temperature, thus avoiding problems associated with differences in device accuracy and precision. Data were recorded every $1 \mathrm{~min}$. These loggers were also tested for moisture using the same technique described above. To measure the microclimate, AT and relative humidity (RH, \%) were measured in 30-s intervals by loggers (Hobo U23-002 logger with RS3 solar radiation shields, accuracy: $\pm 0.2^{\circ} \mathrm{C}$ and $\pm 2.5 \%$, resolution: $\pm 0.02^{\circ} \mathrm{C}$ and 0.05\%; Onset Computer Corp., Pocasset, MA) attached to the right-side wall of the pen (approximately $2 \mathrm{~m}$ away from the nozzle, $1.5 \mathrm{~m}$ high from the ground). Temperature-humidity index (THI) was calculated using the following equation from Kelly and Bond (1971):

$$
\begin{aligned}
\mathrm{THI}=(1.8 \times \mathrm{AT}+32)-[(0.55-0.0055 \times \mathrm{RH}) \\
\\
\times(1.8 \times \mathrm{AT}-26)] .
\end{aligned}
$$

A portable weather station (WS-16; Novalynx Corp., Auburn, CA) was placed in an open area nearby the testing area (approximately $50 \mathrm{~m}$ away) recording AT and black globe temperatures $\left(\mathbf{B G T},{ }^{\circ} \mathrm{C}\right)$, wind speed (WS, m/s), RH, solar radiation $\left(\mathrm{W} / \mathrm{m}^{2}\right)$, and precipitation ( $\mathrm{mm}$ ) every $5 \mathrm{~min}$. In addition to THI, we calculated heat load index (HLI) using the following equation (Gaughan et al., 2008):

$$
\begin{gathered}
\text { If } \mathrm{BGT}>25, \mathrm{HLI}=[8.62+(0.38 \times \mathrm{RH}) \\
+(1.55 \times \mathrm{BGT})+\exp (-\mathrm{WS}+2.4)-0.5 \times \mathrm{WS}] \\
\text { else, } \mathrm{HLI}=[10.66+(0.28 \times \mathrm{RH}) \\
+(1.3 \times \mathrm{BGT})-\mathrm{WS}] .
\end{gathered}
$$

\section{Data Management and Statistical Analysis}

Statistical procedures were carried out using SAS software (SAS Institute, 2009). All data were screened to confirm the normality and homoscedasticity of variances. The spray strategies (frequency, time on and off) were analyzed using a series of models described in Table 2.

The effects of each spray strategy on microclimate and physiological variables were tested using the cow averages $(n=20)$ per treatment. For all measurements, we compared the difference between the baseline and the end of the treatment period (thus, min -1 and 45), except for BT duration, for which we calculated the time for the BT to reach start baseline values. For water temperature, we used the mean temperature generated during the 45-min period. For each model tested, the treatment effects for all the dependent variables were evaluated using mixed models (PROC MIXED; Table 2). Each model used variance components as the covariance structure, with fixed effects for treatment and random effects for cow. Degrees of freedom were estimated using the containment method ( df test $=2$, $\mathrm{df}$ error $=38$; except for water temperature df test $=$ 1 , df error $=19)$. Pairwise comparisons were obtained using PDIFF statement.

Similar models were used to evaluate the weather effects (AT, THI, WS, and HLI averages recorded during the treatment period; all treated as a fixed term) on physiological measures except that we used each value obtained, and we included cow and its interaction with the fixed terms in the random effects ( $\mathrm{df}$ test $=1$, df error $=19$ ). Slopes (i.e., the magnitude of change in each physiological measure caused per unit increase of each weather variable) were obtained through the ESTIMATE statement.

\section{RESULTS}

\section{Weather}

A summary of weather conditions during $24 \mathrm{~h}$ and the experimental period is given in Table 3. During the experimental period, rainfall was $0 \mathrm{~mm}$.

Table 2. Description of the mixed models tested based on the spray strategies evaluated

\begin{tabular}{ll}
\hline Spray strategy tested & Spray treatment comparison ${ }^{1}$ \\
\hline Spray frequency & 10 vs. 5 cycles $(74 \mathrm{~L})$ \\
Spray frequency & 6 vs. 3 cycles $(44 \mathrm{~L})$ \\
Time on & 1.5 vs. 3 min \\
Time off & 3 vs. 6 min \\
Time off & 6 vs. 12 min \\
\hline
\end{tabular}

${ }^{1}$ Shade only (control) treatment was also included in these comparisons. 
Table 3. Summary (averages of daily mean, minimum, and maximum) of weather conditions during $24 \mathrm{~h}$ and the experimental period (1130 to $1215 \mathrm{~h}$ and 1430 to $1515 \mathrm{~h})$

\begin{tabular}{|c|c|c|c|c|c|c|}
\hline Weather variable & \multicolumn{3}{|c|}{ 24-h period } & \multicolumn{3}{|c|}{ Experimental period } \\
\hline Relative humidity (\%) & $41 \pm 21$ & 19 & 70 & $26 \pm 13$ & 20 & 32 \\
\hline Heat load index & $67 \pm 19$ & 44 & 94 & $86 \pm 9$ & 80 & 93 \\
\hline Temperature-humidity index & $68 \pm 6$ & 58 & 76 & $74 \pm 4$ & 71 & 75 \\
\hline Wind speed (m/s) & $1.2 \pm 0.9$ & 0.1 & 3.1 & $1.7 \pm 0.8$ & 0.8 & 2.6 \\
\hline
\end{tabular}

\section{Spray Water Temperature}

Water temperature at the nozzle outlet ranged from 20 to $32.6^{\circ} \mathrm{C}\left(\right.$ mean $\left.=26.1 \pm 1.8^{\circ} \mathrm{C}\right)$. The temperature of the water sprayed was similar across treatments, except for spray strategies where water was held off for less time. Water tended to be slightly cooler when spraying cows for 1.5 min every 3 min compared with spraying them 1.5 min every $6 \min \left(25.5\right.$ vs. $26.3^{\circ} \mathrm{C}, P$ $=0.06)$.

\section{Overall Cooling Effectiveness of the Water Strategies Used}

Spraying water reduced AT surrounding the leg and responses to heat load in cattle more than shade alone $(P<0.01$, Table 4$)$. At the end of $45 \mathrm{~min}$, spray treatments resulted in $\mathrm{BT}$ ranging from 38.7 to $38.5^{\circ} \mathrm{C}$ (Figure 1a; average starting baseline $=38.9^{\circ} \mathrm{C}$ ) and $\mathrm{RR}$ ranging from 52 to 62 breaths/min (Figure 1b; average baseline $=72$ breaths $/ \mathrm{min})$. Skin temperature at the leg and shoulder ranged from 34.5 to $35.4^{\circ} \mathrm{C}$ (average starting baseline $=35.9^{\circ} \mathrm{C}$, Figure 1c) and 33.4 to $34.2^{\circ} \mathrm{C}$ (average baseline $=36.6^{\circ} \mathrm{C}$, Figure $1 \mathrm{~d}$ ), respectively. The AT surrounding the leg averaged $28.9^{\circ} \mathrm{C}$ before the treatments were applied, and was reduced to 28.3 to $28.8^{\circ} \mathrm{C}$ after water was sprayed. Pen microclimate also was different for shade-only treatments $(P<0.02$, Table 4). Pen AT and RH ranged, respectively, from 28.9 to $29.6^{\circ} \mathrm{C}$ and 32.9 to $36.4 \%$ at the end of the treatment period (average starting baseline $=29.3^{\circ} \mathrm{C}$ and $34.3 \%$, respectively). Pen THI was 74 at the baseline, and ranged from 74 to 75 after all the treatments were applied.

\section{Microclimate and Physiological Responses to Different Spray Strategies}

Spray Frequency. When using the same water volume ( $\sim 44$ or $74 \mathrm{~L} / 45 \mathrm{~min}$ ), spraying water more often (thus reducing both times on and off) did not affect BT or the time it took to return to baseline values $(P \geq$ $0.30)$. This strategy also did not affect leg temperature or pen AT, RH, or THI $(P \geq 0.11)$. More frequent spray tended to reduce $\mathrm{RR}(P \leq 0.08)$, regardless of the model tested. When comparing strategies that used $74 \mathrm{~L}$ of water $/ 45 \mathrm{~min}$, spraying water more often also tended to reduce shoulder temperature and AT surrounding the leg $(P=0.09$; Table 4$)$ compared with spraying it less often (10 vs. 5 cycles/45 min).

Time On. Spraying water for 3 min more effectively reduced $\mathrm{BT}$ than spraying it for $1.5 \mathrm{~min}$ (time off $=6$ min for both treatments), keeping temperature below baseline values for additional $16 \mathrm{~min}(P<0.01)$. Spraying water for longer (thus, using extra $30 \mathrm{~L}$ of water) also reduced leg temperature $(P=0.02)$. There were no treatment differences for RR, shoulder temperature, AT surrounding the leg, or pen AT, RH, or THI $(P \geq$ 0.11 ; Table 4).

Time Off. Reducing time off from 6 to 3 min or from 12 to 6 min (after 1.5 or 3 min of spray, respectively) more effectively reduced BT, keeping it below baseline values for longer. Also, shortening time off (i.e., increasing water use from $\sim 44$ to $74 \mathrm{~L} / 45 \mathrm{~min}$ ) reduced leg temperature and pen THI $(P<0.05)$ and tended to reduce RR and pen AT $(P \leq 0.08)$ for both models tested. Shoulder temperature and AT surrounding the leg were only lower when off times were reduced from 6 to 3 min $(P \leq 0.05$, Table 4$)$. No RH differences were found across treatments $(P \geq 0.41$, Table 4$)$.

\section{Weather Effects}

Treatment by weather interactions were found for all measurements taken. However, the majority of these interactions were differences in response between spray treatments and shade alone. Differences among spray treatments for the magnitude of the responses (as indicated by the slopes obtained) were found when manipulating time on and off. Spraying cows for 3 min $(6 \mathrm{~min}$ off) or allowing them to dry for 3 min (after $1.5 \mathrm{~min}$ 
spray) reduced BT as AT (Figure 2) and THI increased (slope range $=-0.01$ to $0.01 ; P<0.04$ ) more markedly than reducing spray duration to $1.5 \mathrm{~min}$ or increasing coat-drying times to $6 \mathrm{~min}$. In addition, reducing time off from 6 to 3 min more markedly reduced shoulder temperature on windier days (slopes $=-0.0$ vs. -0.7 ; $P=0.01$, Figure 3).

Overall, weather affected leg temperature and pen AT more markedly than the other measures evaluated. For all models tested, these measures increased on hotter days (slope range: leg temperature $=0.02$ to 0.04 , pen $\mathrm{AT}=0.03$ to $0.07, P \leq 0.02$ ), and decreased on windier days (slope range: leg temperature $=-0.029$ to -0.034 , pen $\mathrm{AT}=-0.027$ to $-0.031, P \leq 0.03$ ). Leg temperature and pen AT also increased with HLI and THI. Shoulder temperature reduction was more pronounced on windier days (slope $=-0.36, P<0.01$ ) only when comparing spray frequency ( 1.5 on, 3 off vs. 3 on, 6 off) and time off (6 vs. 12 min). Wind speed also reduced the AT surrounding the leg (slope range $=-0.11$ to $-0.23, P \leq 0.04)$ when comparing spray frequency (1.5 on, 3 off vs. 3 on, 6 off), time off ( 3 vs. $6 \mathrm{~min})$, and spray duration. The AT surrounding the leg also increased on warmer days (HLI, slope range $=0.00$ to $0.02, P \leq 0.01)$ in all models tested. Body temperature tended to increase on warmer days (AT, THI, and HLI; slope range $=0.00$ to $0.01, P \leq 0.08$ ) and to decrease on windier days (slope $=-0.04, P$ $\leq 0.07$ ) when testing time-off models (3 vs. $6 \mathrm{~min}$ ). Body temperature was increased when THI and HLI increased (slope range: 0.00 to $0.01, P \leq 0.04$ ) when comparing models of spray frequency ( 6 vs. 3 cycles).

\section{DISCUSSION}

Irrespective of the treatment applied, all spray strategies were relatively effective in reducing heat load after $45 \mathrm{~min}$. With few exceptions, no differences were found when spraying cows with the same water volume more often. In this study, spraying water for longer or holding it off for less time more effectively cooled the cows and decreased AT surrounding the leg compared with strategies that used less water ( $\sim 74$ vs. $44 \mathrm{~L} / 45$ min). Different spray strategies did not affect pen $\mathrm{RH}$ and had minimal biological effect on pen THI, likely because air could still flow through the testing area.

\section{Cooling Effectiveness of the Strategies Used}

In this experiment, cows were sprayed for $45 \mathrm{~min}$, which corresponds to the duration of the average feeding bout or time cows spend at the feed bunk (36 to 49 min/event; Tolkamp et al., 2000; DeVries et al., 2003; Tresoldi et al., 2016). Independent of the water volume 
Treatments (time on $\mid$ off): $\bullet 1.5|3 \quad \Delta 1.5| 6 \quad \Delta 3|12 \quad 03| 6 \quad \square$ Shade only
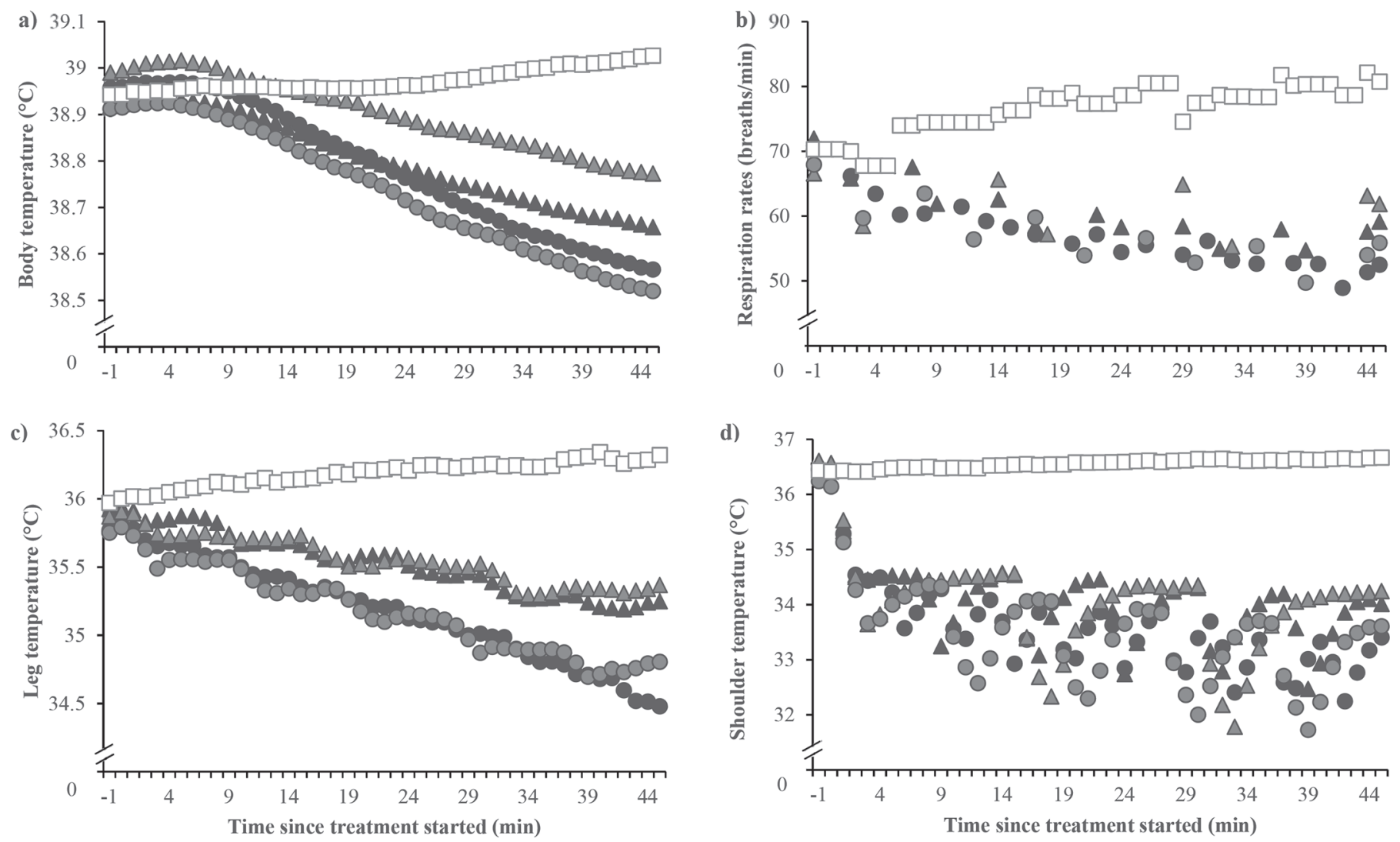

Figure 1. Least squares means of (a) body temperature, (b) respiration rates, and skin temperature at (c) leg surface and (d) shoulder in response to spray strategies varying in time on and off (on off, min): 1.5 $3 ; 1.5|6 ; 3| 6$; and $3 \mid 12$. Measurements include values at baseline and up to the end of treatment (45 min). Similar symbols indicate same water volume (circles $=74 \mathrm{~L} / 45 \mathrm{~min}$; triangles $=44 \mathrm{~L} / 45 \mathrm{~min}$ ), and color indicates treatments where water was on for 1.5 (black) versus 3 (gray) $\min (\mathrm{n}=20$ cows).

and strategy used, cows were relatively cool after $45 \mathrm{~min}$ of spray. Their BT was, on average, $38.7^{\circ} \mathrm{C}$ at the most, which is comparable to the mean BT of lactating cows that have free access to feed bunks fitted with soakers over $24 \mathrm{~h} / \mathrm{d}$ (Chen et al., 2013). In addition, on average, their RR was below 62 breaths/min, comparable to the lower range found on California farms that provided heat abatement resources in summer (Tresoldi et al., 2017). These measures were also relatively lower than in other studies that used less water. For example, BT was at least $0.4^{\circ} \mathrm{C}$ lower than reported by Chen et al. (2015), when spraying unshaded cows for $1 \mathrm{~h}$ using $59 \mathrm{~L}$ of water (minimum BT average $=39.1^{\circ} \mathrm{C}$ ), and at least $0.6^{\circ} \mathrm{C}$ lower than reported by Brouk et al. (2003), when spraying cows for $1.5 \mathrm{~h}$ using $23.4 \mathrm{~L}$ of water (minimum BT average $=39.3^{\circ} \mathrm{C}$ ). Shoulder and leg temperatures found in this study at the end of the 45-min treatment were at least $1.0^{\circ} \mathrm{C}$ lower than those described by Chen and colleagues (2015). These differences could be attributed to the lack of shade provision in the 2015 experiment.

In addition, for the treatments that used more water in this study (74 L/45 min), cows maintained their BT below the baseline for at least 66 min (maximum: 75 min), whereas the treatments delivering $44 \mathrm{~L}$ of water/45 min were below this level for a minimum of 46 min (maximum: $50 \mathrm{~min}$ ), on average. Thus, using additional $30 \mathrm{~L}$ of water $/ 45$ min maintained the BT below baseline for up to extra $25 \mathrm{~min}$. The upper range found in our study was 20 min longer than reported in previous studies (Chen et al., 2015), but at least $1 \mathrm{~h}$ lower than the residual effects of spray treatment described by Flamenbaum et al. (1986). How long spray keeps cows below baseline BT may be affected by the amount of cooling provided. For example, when spray causes BT to drop below baseline by $\sim 1.0^{\circ} \mathrm{C}$, the benefits last for $\sim 120$ min (Flamenbaum et al., 1986). In contrast, when spray reduces body temperature by approximate- 
a) Time on: 1.5 vs. $3 \min (6 \mathrm{~min}$ off $)$

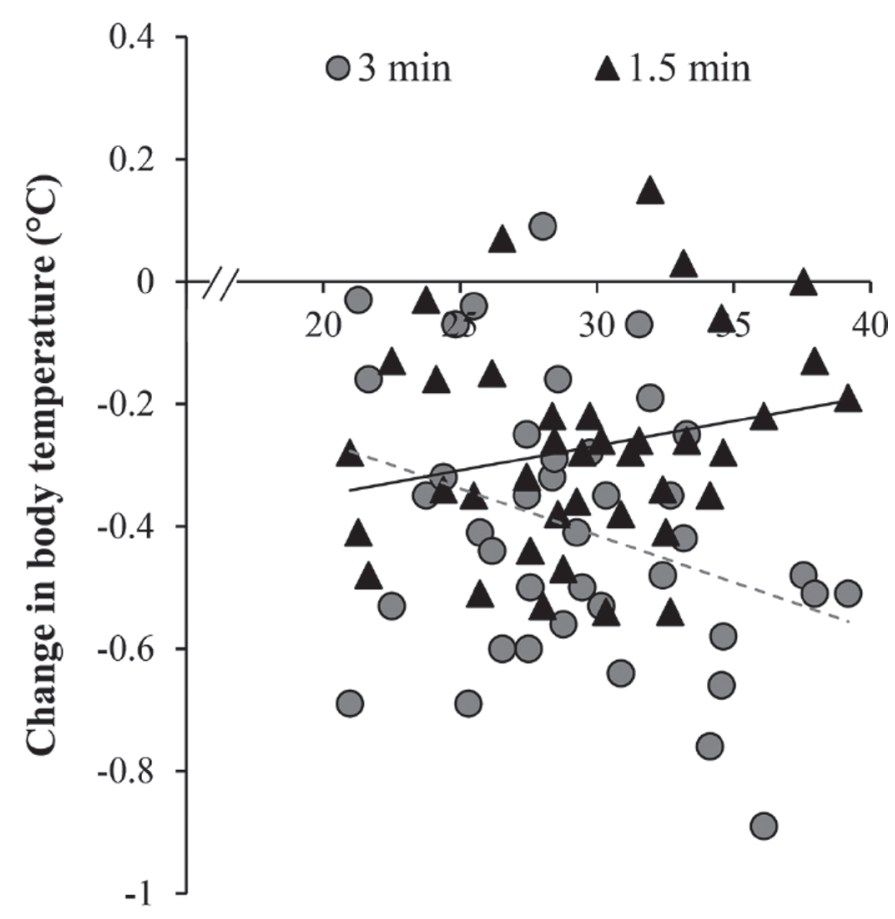

b) Time off: 3 vs. $6 \min (1.5 \mathrm{~min}$ on $)$

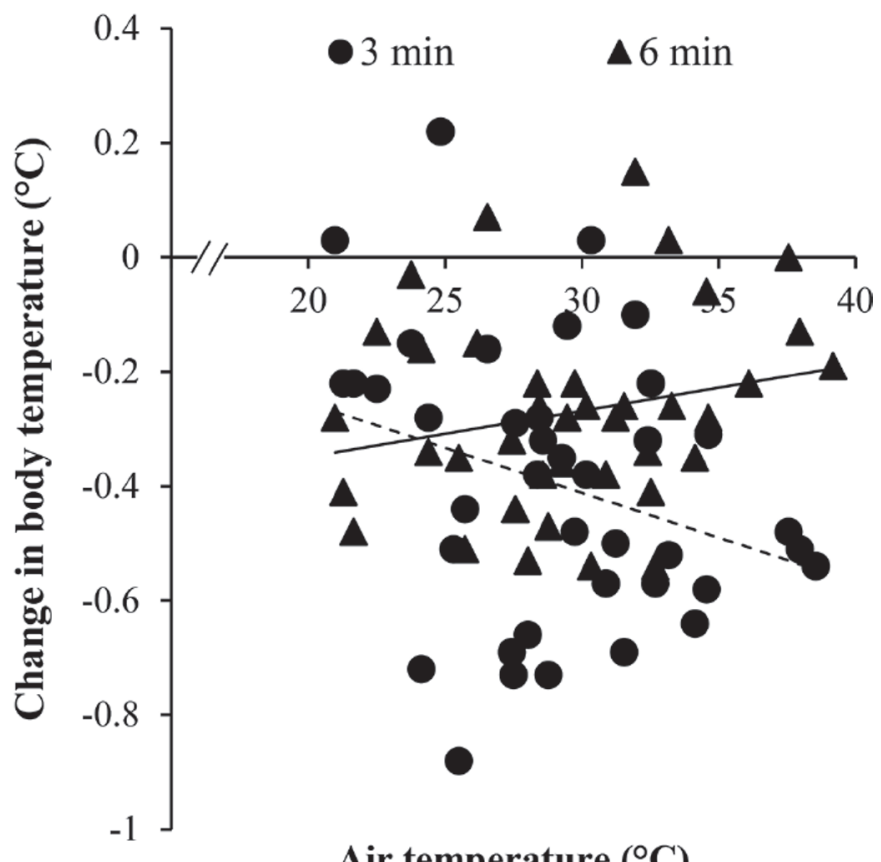

Figure 2. Interaction between air temperature and changes in body temperature when spraying cows intermittently for 45 min using (a) 2 durations of spray on (1.5 vs. $3 \mathrm{~min}$ ) and (b) 2 durations of spray off (3 vs. $6 \mathrm{~min}$ ). Dashed lines indicate treatments that used more water. Both lines represent the best fit for linear equations ( $\mathrm{n}=20$ cows, measured $2 \mathrm{~d}$ /treatment).

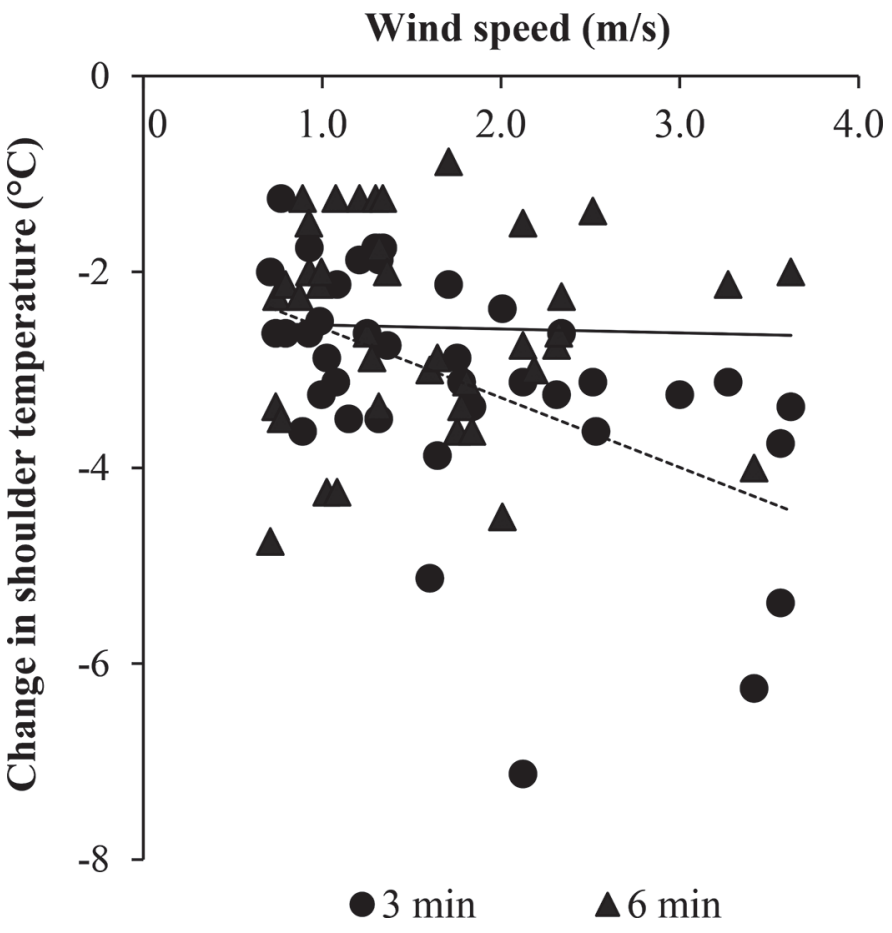

Figure 3. Interaction between wind speed and changes in shoulder skin temperature when spraying cows intermittently for 45 min using 2 durations of spray off ( 3 vs. 6 min, after 1.5 min of spray on). Dashed lines indicate treatments that used more water and represent the best fit for linear equations $(n=20$ cows, measured $2 \mathrm{~d}$ /treatment).

ly $0.1^{\circ} \mathrm{C}$, this effect lasts only for $47 \mathrm{~min}$ (Chen et al., 2015). Our findings are intermediate, both in terms of the amount of change and the duration of the effect. However, our study is unique in terms of the amount of overall cooling provided. In both of the previous studies, BT at the end of the water treatment was $\geq 39.1^{\circ} \mathrm{C}$, which is comparable to the mean BT of cows with no access to sprayed water (Chen et al., 2013), whereas our cows had a mean $\mathrm{BT} \leq 38.7^{\circ} \mathrm{C}$.

We speculate that optimizing cooling strategies while cows are at the feed bunk may be beneficial for other aspects of cattle welfare. If cooling benefits persist beyond a feeding bout, cows will likely have more opportunities to choose what to do next. For example, cows often choose to lie down after feeding (DeVries et al., 2005) but if they are hot they may spend more time at the feed bunk area to obtain more cooling (Chen et al., 2013). Cows in California dairies spent up to $2.6 \mathrm{~h}$ at the feed bunk in a single visit when sprayed water was provided (Tresoldi et al., 2016). This may have negative consequences for their hoof health, because cows may spend more time standing on wet, concrete floors. These factors increase the risk of lameness (Vanegas et al., 2006; Bell et al., 2009). Thus, better understanding of the downstream effects and possible benefits of improved cooling is needed. 


\section{Spray Frequency}

To our knowledge, this is the first study to examine the effects of spray frequency while controlling for water volume. When using the same amount of water, spray frequency did not affect BT (and thus, the time BT took to return to baseline values) or leg temperature. Spraying cows more often tended to reduce RR but the difference between treatments was $<10$ breaths/min. The biological relevance of such a difference is unclear, especially in this situation where $\mathrm{RR}$ was relatively low ( $\leq 62$ breaths/min). In addition, spray frequency tended to affect AT surrounding the leg and shoulder temperature when more water was used (74 L/45 min). These tendencies, however, may indicate that these measures (including RR) are more plastic or sensitive to direct spray than BT, as shown by Chen et al. (2015). For example, as water is sprayed, RR decreases and then, when no additional cooling is provided after water is turned off, it increases progressively until the next spray application (Chen et al., 2015; Tresoldi et al., 2018). When spraying water more often, we also reduced the time off ( 3 vs. $6 \mathrm{~min}$ ), shortening the time these measures (e.g., RR, AT surrounding the leg) had to return to baseline values.

\section{Time On and Off}

Cow cooling was more effective when water was on for longer (3 vs. $1.5 \mathrm{~min}$ ) or was held off for less time (6 vs. $12 \mathrm{~min}$ or 3 vs. $6 \mathrm{~min}$ ) in this study. Thus, using more water (an extra $30 \mathrm{~L} / 45 \mathrm{~min}$ ) resulted in more cooling at the end of 45 min.

Time On. Reductions in BT and skin temperature of the leg were more pronounced when spraying cows for 3 versus $1.5 \mathrm{~min}$ when the time off was constant (6 min; thus, 74 vs. $44 \mathrm{~L}$ of water $/ 45 \mathrm{~min}$ ), and these effects were more marked when AT and THI increased. A similar pattern was described by Flamenbaum et al. (1986) and Morrison et al. (1981), where spraying water for longer improved cow cooling (by reducing BT) and feed intake, respectively. These results suggest that heat-exchange mechanisms occur while water is being sprayed. In another study, we found that temperature of the water dripping from the cows was higher than the temperature of the water being sprayed, suggesting that the water carries some of the heat away from the cows' body surface (Tresoldi et al., 2018).

Time Off. Overall, reducing the time off (from 12 to $6 \mathrm{~min}$, or from 6 to $3 \mathrm{~min}$ ) reduced pen AT, THI, and heat load in cattle, based on most of the physiological parameters evaluated. A similar pattern was described by Brouk et al. (2003) when comparing off times of 4, 9, and $14 \mathrm{~min}$ (after $1 \mathrm{~min}$ of spray). However, in their study, pairwise comparisons were not described. When comparing reduction in off times from 6 to 3 min, using more water also minimized the negative effects of AT and THI on BT, and further reduced shoulder temperature on windier days. As expected, cooling was enhanced when reducing time off, likely because more frequent spray applications prevented heat load from returning to baseline values. Other studies have found that once water is turned off, cows usually do not experience further heat abatement (Chen et al., 2015; Tresoldi et al., 2018), at least in environments without forced air movement. Even though pen THI was lower when less time elapsed between spray applications, differences were $<1$ unit. It is unlikely that such differences in THI were responsible for differences in BT when comparing these strategies. Other studies have shown that every 1-unit of increase in THI causes BT to increase from 0.05 to $0.1^{\circ} \mathrm{C}$ (Chen et al., 2015, 2016).

\section{CONCLUSIONS}

When applying water intermittently over $45 \mathrm{~min}$ on restrained cattle, spray frequency had a minimal effect on responses to heat load when using the same water volume. In this experiment, spraying cows for longer or reducing the time off, and thus using more water, were effective strategies to reduce AT surrounding the leg and to improve cow cooling. However, regardless of the spray strategy used ( $\sim 44$ vs. $74 \mathrm{~L}$ of water/nozzle), all cows were relatively cool at the end of treatment. These results suggest that there are opportunities to adjust spray timing to improve cow cooling and water-use efficiency. More information is needed to understand how cows respond to different spray strategies in loose housing systems where they can choose how to use it.

\section{ACKNOWLEDGMENTS}

We are grateful to those who assisted with data collection: Pauline Lima (supported by the Science Without Borders Program, Brasilia, Brazil), Emma Williams, Adolfo Porras, Bradley Whelchel, Tony Phan, Amanda Crofton, Camille Pizarro, Che Wei Hsu, Jason Tong, Jessica Schlarbaum, Karen Sin, Kassandra Mejia and Veronica Wang (all affiliated with UC Davis at the time of the study). Many thanks also to Doug Gisi, Maria Patino, and the staff and interns of the UC Davis Dairy and Teaching Facility, Daniel Sehnert, Frank Sauers, Jose Villasenor, Joy Mench, Neil Willits, Floriana Petrone, Parsa Taheri, and Adrien DurandPetiteville (all affiliated with UC Davis at the time of the study). We gratefully acknowledge the financial support of CAPES Foundation (Brasilia, Brazil; process BEX 0764/12-4, awarded to G. Tresoldi), Jastro 
Shields Award (Davis, CA), USDA multi-state research project W2173 and W3173 (Washington, DC), and the infrastructure support of the Department of Animal Science, and the College of Agricultural and Environmental Sciences of the University of California, Davis.

\section{REFERENCES}

Bell, N. J., M. J. Bell, T. G. Knowles, H. R. Whay, D. J. Main, and A. J. Webster. 2009. The development, implementation and testing of a lameness control programme based on HACCP principles and designed for heifers on dairy farms. Vet. J. 180:178-188. https:// doi.org/10.1016/j.tvjl.2008.05.020.

Brouk, M. J., J. F. Smith, and J. P. Harner III. 2003. Effect of sprinkling frequency and airflow on respiration rate, body surface temperature and body temperature of heat stressed dairy cattle. Pages 263-268 in 5th Int. Dairy Housing, Fort Worth, TX. Am. Soc. Agric. Eng., St. Joseph, MI.

Chen, J. M., K. E. Schütz, and C. B. Tucker. 2013. Dairy cows use and prefer feed bunks fitted with sprinklers. J. Dairy Sci. 96:50355045. https://doi.org/10.3168/jds.2012-6282.

Chen, J. M., K. E. Schütz, and C. B. Tucker. 2015. Cooling cows efficiently with sprinklers: Physiological responses to water spray. J. Dairy Sci. 98:6925-6938. https://doi.org/10.3168/jds.2015-9434.

Chen, J. M., K. E. Schütz, and C. B. Tucker. 2016. Cooling cows efficiently with water spray: Behavioral, physiological, and production responses to sprinklers at the feed bunk. J. Dairy Sci. 99:4607-4618. https://doi.org/10.3168/jds.2015-10714.

DeVries, T. J., M. A. G. von Keyserlingk, and K. A. Beauchemin. 2005. Frequency of feed delivery affects the behavior of lactating dairy cows. J. Dairy Sci. 88:3553-3562. https://doi.org/10.3168/ jds.S0022-0302(05)73040-X.

DeVries, T. J., M. A. G. von Keyserlingk, D. M. Weary, and K. A. Beauchemin. 2003. Measuring the feeding behavior of lactating dairy cows in early to peak lactation. J. Dairy Sci. 86:3354-3361. https://doi.org/10.3168/jds.S0022-0302(03)73938-1.

Flamenbaum, I., D. Wolfenson, M. Mamen, and A. Berman. 1986 Cooling dairy cattle by a combination of sprinkling and forced ventilation and its implementation in the shelter system. J. Dairy Sci. 69:3140-3147. https://doi.org/10.3168/jds.S0022-0302(86)80778 $-0$.

Gaughan, J. B., T. L. Mader, S. M. Holt, and A. Lisle. 2008. A new heat load index for feedlot cattle. J. Anim. Sci. 86:226-234. https: //doi.org/10.2527/jas.2007-0305.

Gebremedhin, K. G., and B. Wu. 2002. Simulation of sensible and latent heat losses from wet-skin surface and fur layer. J. Therm. Biol. 27:291-297. https://doi.org/10.1016/S0306-4565(01)00091-2.

Hillmann, P. E., K. G. Gebremedhin, A. Parkhurst, J. Fuquay, and S. Willard. 2001. Evaporative and convective cooling of cows in a hot and humid environment. Pages 343-350 in 6th Int. Symp. Livestock Environment, Louisville, KY. Am. Soc. Agric. Eng., St. Joseph, MI.

Keister, Z. O., K. D. Moss, H. M. Zhang, T. Teegerstrom, R. A Edling, R. J. Collier, and R. L. Ax. 2002. Physiological responses in thermal stressed Jersey cows subjected to different management strategies. J. Dairy Sci. 85:3217-3224. https://doi.org/10.3168/jds .S0022-0302(02)74410-X.
Kelly, C. F., and T. E. Bond. 1971. Bioclimatic factors and their measurement. Page 77 in A Guide to Environmental Research on Animals. National Academies Press, Washington, DC.

Kendall, P. E., G. A. Verkerk, J. R. Webster, and C. B. Tucker. 2007. Sprinklers and shade cool cows and reduce insect-avoidance behavior in pasture-based dairy systems. J. Dairy Sci. 90:3671-3680. https://doi.org/10.3168/jds.2006-766.

Means, S. L., R. A. Bucklin, R. A. Nordstedt, D. K. Beede, D. R. Bray, C. J. Wilcox, and W. K. Sanchez. 1992. Water application rates for sprinklers and fan dairy cooling system in hot, humid climates. Trans. ASAE 8:374-378. https://doi.org/10.13031/2013.26080.

Morrison, S. R., M. Prokop, and G. P. Lofgreen. 1981. Sprinkling cattle for heat stress relief: Activation temperature, duration of sprinkling and pen area sprinkled. Trans. ASAE 24:1299-1300. https://doi.org/10.13031/2013.34438.

Perano, K. M., J. G. Usack, L. T. Angenent, and K. G. Gebremedhin. 2015. Production and physiological responses of heat-stressed lactating dairy cattle to conductive cooling. J. Dairy Sci. 98:52525261. https://doi.org/10.3168/jds.2014-8784.

SAS Institute. 2009. SAS/STAT 9.2 User's Guide. Vol. 2nd. SAS Institute Inc., Cary, NC.

St-Pierre, N. R., B. Cobanov, and G. Schnitkey. 2003. Economic losses from heat stress by US livestock industries. J. Dairy Sci. 86:E52E77. https://doi.org/10.3168/jds.S0022-0302(03)74040-5.

Stull, C. L., L. L. McV. Messam, C. A. Collar, N. G. Peterson, A. R. Castillo, B. A. Reed, K. L. Andersen, and W. R. VerBoort. 2008. Precipitation and temperature effects on mortality and lactation parameters of dairy cattle in California. J. Dairy Sci. 91:45794591. https://doi.org/10.3168/jds.2008-1215.

Tolkamp, B. J., D. P. N. Schweitzer, and I. Kyriazakis. 2000. The biologically relevant unit for the analysis of short-term feeding behavior of dairy cows. J. Dairy Sci. 83:2057-2068. https://doi.org/ 10.3168/jds.S0022-0302(00)75087-9.

Tresoldi, G., K. E. Schütz, and C. B. Tucker. 2016. Assessing heat load in drylot dairy cattle: Refining on-farm sampling methodology. J. Dairy Sci. 99:8970-8980. https://doi.org/10.3168/jds.2016-11353.

Tresoldi, G., K. E. Schütz, and C. B. Tucker. 2017. Cow cooling on commercial drylot dairies: A description of 10 farms in California. Calif. Agric. 71:249-255. https://doi.org/10.3733/ca.2017a0042.

Tresoldi, G., K. E. Schutz, and C. B. Tucker. 2018. Cooling cows with sprinklers: Spray duration affects physiological responses to heat load. J. Dairy Sci. 101:4412-4423. https://doi.org/10.3168/ jds.2017-13806.

Urdaz, J. H., M. W. Overton, D. A. Moore, and J. E. P. Santos. 2006. Technical note: Effects of adding shade and fans to a feedbunk sprinkler system for preparturient cows on health and performance. J. Dairy Sci. 89:2000-2006. https://doi.org/10.3168/jds .S0022-0302(06)72267-6.

USDA. 2016. Dairy 2014, Dairy cattle management practices in the United States, 2014. USDA Animal and Plant Health Inspection Service, Veterinary Services, Center for Animal Epidemiology and Health (APHIS-VS-CEAH), Fort Collins, CO.

Vanegas, J., M. Overton, S. L. Berry, and W. M. Sischo. 2006. Effect of rubber flooring on claw health in lactating dairy cows housed in free-stall barns. J. Dairy Sci. 89:4251-4258. https://doi.org/10 .3168/jds.S0022-0302(06)72471-7.

von Keyserlingk, M. A. G., N. P. Martin, C. J. Sniffen, J. P. Harner III, A. D. Wright, and S. I. Smith. 2013. Invited review: Sustainability of the US dairy industry. J. Dairy Sci. 96:5405-5425. https: //doi.org/10.3168/jds.2012-6354. 